\title{
Utilização de calcário em plantio direto e convencional de soja e milho em Latossolo Vermelho
}

\author{
Leo Nobre de Miranda ${ }^{(1)}$, Jeanne Christine Claessen de Miranda(1), Thomaz Adolpho Rein ${ }^{(1)}$ \\ e Antonio Carlos Gomes ${ }^{(1)}$
}

\begin{abstract}
(1)Embrapa Cerrados, Km 18, BR 020, Caixa Postal 08223, CEP 73301-970 Planaltina, DF. E-mail: leo@cpac.embrapa.br, jeanne@cpac.embrapa.br, rein@cpac.embrapa.br, acarlos@cpac.embrapa.br
\end{abstract}

\begin{abstract}
Resumo - Os solos de cerrado apresentam alta acidez e alumínio tóxico, por isso é necessário aplicar calcário para obter boas produtividades das culturas de grãos. O objetivo deste trabalho foi estudar os efeitos da calagem e de formas de aplicação do calcário na correção da acidez de um Latossolo Vermelho, e na produtividade da soja e do milho, cultivados em rotação, nos sistemas de plantio convencional (aração e gradagem) e de plantio direto (sem preparo). Plantas de cobertura foram cultivadas de forma intercalada: mucuna após soja e milheto após milho. No plantio convencional, utilizou-se um tratamento sem plantas de cobertura, com calcário incorporado. $\mathrm{O}$ veranico prejudicou a soja no primeiro cultivo, porém a produtividade aumentou com a calagem no terceiro cultivo. Nos segundo e quarto cultivos, a produtividade do milho aumentou com a calagem, sendo superior no plantio convencional apenas no segundo cultivo. No plantio direto, os tratamentos sem incorporação do calcário mostraram produtividades de milho inferiores em relação aos tratamentos com incorporação do calcário. A resposta do milho ao parcelamento do calcário foi proporcional às quantidades parceladas e incorporadas. A ausência da mucuna no plantio convencional resultou em redução de produtividade do milho. O calcário aplicado na superfície alterou as condições químicas do solo, principalmente na profundidade de $0-5 \mathrm{~cm}$.
\end{abstract}

Termos para indexação: Glycine max, Zea mays, mucuna, milheto, calagem, cerrado.

\section{Lime under no-tillage and conventional planting systems for soybean and corn in Red Latosol (Oxisol)}

\begin{abstract}
Cerrado soils are acid with toxic levels of aluminum and, in order to overcome these conditions to grow crops, lime is necessary. This experiment evaluated the effects of lime levels and methods of lime application on the grain production of soybean and corn in rotation, under conventional (disk plowing and harrowing) and no-tillage planting systems in a Red Latosol (Oxisol). Cover crops were planted in the dry season; mucuna was cultivated after soybean and millet after corn. One lime treatment was included without cover crop under the conventional system. The occurrence of a dry spell period caused reduction in soybean yield in the first crop, but yield increases were observed due to lime application, under both systems, in the third crop. In the second and fourth crops, corn grain yields increased with lime levels, and were higher in the conventional system in the second crop. In no-tillage system, lime levels without incorporation produced less corn grain yield compared to incorporated lime. The corn response to split lime application was proportional to the incorporated lime levels. The exclusion of cover crops under the conventional system promoted corn grain yield reduction. Surface lime applications affected the soil chemical characteristics mainly at the $0-5 \mathrm{~cm}$ depth.
\end{abstract}

Index terms: Glycine max, Zea mays, mucuna, millet, liming, cerrado soil.

\section{Introdução}

Os solos de cerrado caracterizam-se pela alta acidez, presença de alumínio em níveis tóxicos e baixa fertilidade (Goedert, 1983), e, por isso, é necessário corrigir a acidez pela aplicação de calcário e fornecer nutrientes, para que se possa obter boas produtividades das culturas, seja no sistema de plantio convencional ou direto.
No cultivo de plantas no sistema de plantio convencional (aração e gradagem), existem alternativas adequadas de recomendação de calagem e de manejo do calcário nos solos de cerrado, ocorrendo um efeito residual significativo desse corretivo, por meio de vários cultivos sucessivos (Gonzalez-Erico et al., 1979; Miranda, 1993). Entretanto, quanto ao cultivo de plantas no sistema plantio direto, em grande expansão na 
região, essas informações são ainda escassas. Dados de outras regiões mostram que nesse sistema de plantio, a calagem pode ser efetuada por meio da incorporação do calcário ao solo, ou em aplicações de manutenção na superfície, sem incorporação, para solos com necessidade pequena de calagem (Rechcigl et al., 1985; Bayer \& Mielniczuk, 1997).

Com o calcário previamente incorporado, a resposta das culturas à calagem tem sido semelhante nos plantios direto e convencional (Arshad \& Gill, 1996), sendo que os métodos de preparo do solo não afetaram o pH e a distribuição de cálcio, magnésio e alumínio trocáveis no perfil do solo (Klepker \& Anghinoni, 1995). Por sua vez, a adição superficial de manutenção de calcário ao solo com o sistema plantio direto tem sido efetiva em melhorar as condições de acidez da camada subsuperficial e aumentar a produtividade de grãos de soja (Oliveira \& Pavan, 1996).

Santos et al. (1995), reaplicando calcário em área cultivada, não observaram diferenças significativas no pH e nos teores de alumínio, cálcio e magnésio trocáveis na camada de $0-20 \mathrm{~cm}$ do solo, com o calcário incorporado ou adicionado na superfície. Pöttker \& Ben (1998) constataram que a aplicação superficial de calcário corrige a acidez do solo, principalmente na camada de $0-5 \mathrm{~cm}$, mas, mesmo assim, observaram aumentos na produtividade de grãos de soja e cevada, possivelmente devido às condições não muito drásticas da acidez na camada subsuperficial do solo. Segundo Caires et al. (1998), a ação neutralizante do calcário aplicado na superfície de áreas já cultivadas vai atingindo gradativamente as camadas mais profundas no perfil do solo, o que faz com que essa prática produza resultados benéficos com o tempo de cultivo.

O objetivo deste trabalho foi estudar os efeitos da calagem e de formas de aplicação do calcário na correção da acidez de um Latossolo Vermelho, e na produtividade da soja e do milho em cultivos alternados em rotação, nos sistemas de plantio convencional com aração e gradagem e de plantio direto, sem preparo do solo.

\section{Material e Métodos}

O trabalho foi iniciado em 1999 na área experimental da Embrapa Cerrados, Planaltina, DF, em Latossolo Vermelho argiloso. As características iniciais do solo $(0-20 \mathrm{~cm})$ foram: $\mathrm{pH}$ em água $(1: 2,5), 5,1$; $0,93 \mathrm{cmol}_{\mathrm{C}} \mathrm{dm}^{-3}$ de $\mathrm{Al}^{3+} ; 0,04 \mathrm{cmol}_{\mathrm{C}} \mathrm{dm}^{-3}$ de $\mathrm{K}^{+}$;
$0,18 \mathrm{cmol}_{\mathrm{C}} \mathrm{dm}^{-3}$ de $\mathrm{Ca}^{2+}+\mathrm{Mg}^{2+} ; 5,8 \mathrm{cmol}_{\mathrm{C}} \mathrm{dm}^{-3}$ de $\mathrm{H}^{+}+\mathrm{Al}^{3+} ; 3,7 \%$ de saturação por bases (V); $27 \mathrm{~g} \mathrm{~kg}^{-1}$ de C; $1,2 \mathrm{mg} \mathrm{dm}^{-3}$ de P; $590 \mathrm{~g} \mathrm{~kg}^{-1}$ de argila; $80 \mathrm{~g} \mathrm{~kg}^{-1}$ de silte; e $330 \mathrm{~g} \mathrm{~kg}^{-1}$ de areia.

Os tratamentos, em número de 12, constituíram-se de doses de calcário proporcionais a $4 \mathrm{t} \mathrm{ha}^{-1}$ $($ PRNT $=100 \%)$ que, de acordo com a análise química, é a quantidade necessária para elevar a saturação por bases desse solo para 50\%. Essas doses foram aplicadas a lanço e incorporadas com plantios direto (PD) e convencional (PC - aração e gradagem), não incorporadas somente com plantio direto, combinando essas duas formas com parcelamento da dose máxima de calcário e somente com plantio direto (Tabela 1). Nos tratamentos parcelados, foram simuladas situações observadas em áreas cultivadas com plantio direto, que necessitam de doses pequenas de calcário para manutenção. A análise do calcário utilizado no experimento mostrou as seguintes características: $24,53 \%$ de Ca, 7,64\% de Mg e 67\% de PRNT.

A soja foi cultivada, seguida de milho, nos períodos chuvosos, com intercalação de plantas de cobertura (mucuna e milheto) nos períodos secos, conforme Silva et al. (1997). O sistema de sucessão de culturas foi: sojamucuna-milho-milheto-soja-mucuna-milho. No plantio convencional, houve um tratamento com $4 \mathrm{t} \mathrm{ha}^{-1}$ de calcário incorporadas, sem plantas de cobertura. Utilizou-se o delineamento experimental de blocos casualizados, com três repetições, em parcelas de $8 \times 15 \mathrm{~m}$.

Tabela 1. Tratamentos de doses e modos de aplicação de calcário estabelecidos em duas etapas: incorporadas (I) em 1999; e aplicadas e não incorporadas (NI) em 2000 antes do primeiro cultivo, sob plantio convencional (PC) e direto (PD), em Latossolo Vermelho argiloso.

\begin{tabular}{cccc}
\hline Tratamento & \multicolumn{3}{c}{ Calcário } \\
\cline { 2 - 4 } & I (1999) & NI $(2000)$ & Total \\
\hline $1^{(1)}$ & 0 & 0 & 0 \\
$2^{(1)}$ & 2 & 0 & 2 \\
$3^{(1)}$ & 4 & 0 & 4 \\
$4^{(2)}$ & 4 & 0 & 4 \\
$5^{(3)}$ & 0 & 2 & 2 \\
$6^{(3)}$ & 0 & 4 & 4 \\
$7^{(3)}$ & 2 & 2 & 4 \\
$8^{(3)}$ & 3 & 1 & 4 \\
$9^{(3)}$ & 0 & $1^{(4)}$ & 4 \\
\hline
\end{tabular}

${ }^{(1)}$ Tratamentos com PC e PD. ${ }^{(2)}$ Tratamento sem plantas de cobertura, somente com PC. (3)Tratamentos somente com PD. (4)Aplicação anual, completando $4 \mathrm{t} \mathrm{ha}^{-1}$ no quarto cultivo. 
A área experimental foi desmatada e preparada por meio de aração e gradagem em junho de 1999. Em setembro desse mesmo ano, foram aplicados os tratamentos de calcário incorporados (I) ao solo, com arado de discos, na profundidade de 0-20 cm. Em dezembro de 1999, foi corrigida a fertilidade do solo de todas as parcelas, inclusive daquelas sem calcário, utilizando-se $240 \mathrm{~kg} \mathrm{ha}^{-1} \mathrm{de}_{2} \mathrm{O}_{5}$ (superfosfato triplo), $100 \mathrm{~kg} \mathrm{ha}^{-1}$ de $\mathrm{K}_{2} \mathrm{O}(\mathrm{KCl})$ e $40 \mathrm{~kg} \mathrm{ha}^{-1}$ de FTE BR-12, aplicados a lanço e incorporados com arado de discos e grade niveladora. A área experimental foi deixada em repouso por um ano, para que se pudesse começar, então, com os plantios direto e convencional em novembro de 2000. Nesse mês foram estabelecidos os tratamentos completos e parciais de doses de calcário não incorporadas (NI). As parcelas com plantio convencional foram preparadas novamente com arado de discos e grade niveladora. Em seguida, foi efetuada a primeira semeadura com plantios direto e convencional de soja (cv. Milena) na densidade de 500.000 plantas ha-1 e espaçamento entre linhas de $0,45 \mathrm{~m}$. As sementes foram submetidas à inoculação de Bradyrhizobium japonicum antes da semeadura (1 kg de inoculante por $40 \mathrm{~kg}$ de sementes).

Em maio de 2001 (período seco), foi semeada a mucuna-preta para cobertura do solo, utilizando-se espaçamento entre linhas de $0,45 \mathrm{~m}$ e $100 \mathrm{~kg} \mathrm{ha}^{-1}$ de sementes. Em novembro do ano agrícola 2001/2002, o milho híbrido Cargill 901 foi plantado, na densidade de 50.000 plantas ha $^{-1}$ e espaçamento entre linhas de 0,90 m. Em maio de 2002, plantou-se milheto (cv. BR 5) para cobertura do solo, com espaçamento entre linhas de $0,45 \mathrm{~m}$ e $30 \mathrm{~kg} \mathrm{ha}^{-1}$ de sementes. Posteriormente, foram efetuados nos mesmos meses, na seqüência, um cultivo de soja no ano agrícola 2002/2003, de mucuna no período seco de 2003 e de milho no ano agrícola 2003/2004. A mucuna e o milheto foram cultivados com plantio direto em toda a área experimental e, a cada setembro, foi passado o Triton em toda a área experimental para triturar a massa verde das plantas. O preparo do solo com aração e gradagem no sistema de plantio convencional foi efetuado somente antes das culturas principais (soja e milho), no início de novembro de cada ano. A partir do primeiro plantio da mucuna, em 2001, foi instalado um sistema de irrigação por aspersão na área. As culturas intercaladas de mucuna e milheto, no período seco, foram cultivadas com irrigação e o milho e a soja, no período chuvoso, receberam irrigação suplementar quando necessária. O plantio de todas as culturas foi realizado por semeadora-adubadora.
A adubação anual de manutenção no sulco de semeadura para soja foi $500 \mathrm{~kg} \mathrm{ha}^{-1}$ da fórmula 0-20-20 e para o milho foi $500 \mathrm{~kg} \mathrm{ha}^{-1} \mathrm{da}$ fórmula 4-14-8, acrescida de $2 \mathrm{~kg} \mathrm{ha}^{-1}$ de $\mathrm{Zn}\left(\mathrm{ZnSO}_{4} \cdot 7 \mathrm{H}_{2} \mathrm{O}\right)$. O milho recebeu ainda, em cobertura, $120 \mathrm{~kg} \mathrm{ha}^{-1}$ de $\mathrm{N}$ (uréia) em duas aplicações de $60 \mathrm{~kg} \mathrm{ha}^{-1}$, aos 35 dias e 45 dias após a emergência. As culturas para cobertura do solo não receberam adubação.

Foram coletadas amostras de solo para análise química (Embrapa, 1979), após um ano da aplicação superficial do calcário, antes do plantio do milho em 2001, nas profundidades de $0-5,5-10$ e $10-20 \mathrm{~cm}$, compostas de 10 subamostras (metade nas entrelinhas e metades nas linhas). Essa amostragem com trado foi efetuada, também, antes do plantio da soja em 2002 e do plantio do milho em 2003. Amostras de folhas de 30 plantas de soja (terceira folha com pecíolo) foram também coletadas no florescimento e amostras de milho (terço central da folha da base da espiga), na fase de pendoamento (Cantarella et al., 1996), para análise de tecido (Malavolta et al., 1997). As avaliações da produção de matéria seca da mucuna e do milheto foram efetuadas somente nos tratamentos com doses totais de calcário. Nos meses de setembro de cada ano, foram coletadas duas subamostras de $1 \mathrm{~m}^{2}$ por parcela antes do trituramento das plantas. A produção de grãos de soja e milho foi avaliada em área útil de 4x10 m, ajustada para $130 \mathrm{~g} \mathrm{~kg}^{-1}$ de umidade e os dados foram submetidos à análise estatística pelos procedimentos do SAS (SAS Institute, 1989). As médias foram comparadas pelo teste de Duncan a 5\% de probabilidade.

\section{Resultados e Discussão}

A ocorrência de $124 \mathrm{~mm}$ de chuva no mês de fevereiro de 2001, com $13 \mathrm{~mm}$ de chuva entre os dias 9 e 24, prejudicou o desenvolvimento da soja do primeiro cultivo, resultando em baixa produtividade de grãos. Nos cultivos seguintes, boas produtividades de milho e soja foram alcançadas, como resposta significativa dessas culturas ao efeito residual das doses de calcário.

Mesmo com a limitação mencionada, houve um aumento crescente de produtividade da soja em 2000/2001, em resposta às doses de calcário incorporadas, tanto no sistema de plantio convencional como direto (Tabela 2). No PD ocorreram as menores produtividades de grãos nos tratamentos 5 e 6, com calcário não incorporado, em comparação com os tratamentos 2 e 3 , com incorporação do calcário. Não houve resposta à aplicação 
de $1 \mathrm{t} \mathrm{ha}^{-1}$ de calcário (tratamento 9) na superfície antes do plantio. Sua produtividade foi semelhante à obtida pelo tratamento sem calcário (tratamento 1) e ambos foram significativamente inferiores aos demais tratamentos, nos dois sistemas de plantio.

No segundo cultivo da soja (2002/2003), ocorreu aumento significativo de produtividade da cultura em resposta às doses de calcário incorporadas, de forma semelhante no PC e no PD. Em todas as doses de calcário, nas diferentes formas de aplicação, a produtividade foi semelhante, e foi superior apenas em relação ao tratamento testemunha. A soja mostrou-se mais tolerante que o milho às condições ácidas do solo, com respostas relativamente menores à aplicação de calcário, de acordo com o citado por Miranda \& Miranda (2000). A produtividade no tratamento sem calcário foi superior no PC, provavelmente em virtude do efeito da incorporação da palhada do milheto. Segundo Wilson \& Hargrove (1986), a incorporação de resíduos vegetais acelera a mineralização da matéria orgânica e a liberação de N para o solo. Entretanto, como a soja foi submetida à inoculação de rizóbio, não se esperaria efeito significativo do provável aumento da disponibilidade de $\mathrm{N}$, oriundo da mineralização da palhada do milheto.

Os menores teores foliares de $\mathrm{Ca}$ e $\mathrm{Mg}$ e maiores de $\mathrm{Mn}$ e Cu da soja ocorreram no tratamento testemunha (Tabela 3). Esse comportamento foi também observado nessa cultura por Novais et al. (1989) e Miranda, (1993). Entretanto, o decréscimo nos teores foliares de Mn e Cu nos tratamentos com calagem não atingiu níveis de deficiência, em decorrência da utilização de adubação de manutenção com micronutrientes.
A resposta do milho ao efeito residual da calagem no ano agrícola 2001/2002 foi sempre superior no PC, com acréscimo médio de $1,1 \mathrm{t} \mathrm{ha}^{-1}$ de grãos nas duas doses de calcário (tratamentos 2 e 3) em relação aos mesmos tratamentos em PD (Tabela 2). A produtividade obtida com $2 \mathrm{t} \mathrm{ha}^{-1}$ de calcário incorporadas em PC foi semelhante à obtida com $4 \mathrm{t} \mathrm{ha}^{-1}$ de calcário incorporadas em PD. Entretanto, no cultivo de 2003/2004, a produtividade do milho nos tratamentos 2 e 3 foi semelhante no PC e PD, e superior em relação ao tratamento testemunha.

A produtividade dos dois cultivos de milho no tratamento sem calcário (1) em PC foi significativamente superior à obtida em $\mathrm{PD}$, provavelmente, por causa dos efeitos da incorporação da mucuna. Costa et al. (1990) observaram que a mucuna incorporada no Latossolo Vermelho-Escuro de cerrado causou acúmulo de $\mathrm{N}$ inorgânico, no solo, $60 \%$ maior que a mucuna deixada na superfície.

O tratamento com 4 t ha ${ }^{-1}$ de calcário incorporadas em PC (tratamento 4), sem plantas de cobertura intercaladas no período seco, é semelhante ao do sistema de plantio convencional, utilizado na região, e permite avaliar a contribuição das plantas de cobertura, em comparação com o tratamento 3 . No tratamento 4 , a produtividade do milho em 2001/2002 foi inferior em 2,27 tha-1 de grãos em relação à mesma dose de calcário com plantas de cobertura no tratamento 3 . No ano agrícola 2003/2004, essa diferença foi de 1,25 t ha-1 $^{-1}$ de grãos.

A incorporação da mucuna pode promover a ciclagem de nutrientes e beneficiar sua absorção pela cultura seguinte (Amabile et al., 1999), além de aumentar a dispo-

Tabela 2. Produtividade de grãos ( $\mathrm{t} \mathrm{ha}^{-1}$ ) de soja cultivar Milena e de milho híbrido Cargill 901, em razão de doses de calcário incorporadas (I) em 1999, aplicadas e não incorporadas (NI) em 2000, antes do primeiro cultivo, sob plantio convencional (PC) e direto (PD), em Latossolo Vermelho argiloso. Médias de três repetições ${ }^{(1)}$.

\begin{tabular}{|c|c|c|c|c|c|c|c|c|c|c|c|}
\hline \multirow[t]{3}{*}{ Tratamentos } & \multicolumn{3}{|c|}{ Calcário $\left(\mathrm{t} \mathrm{ha}^{-1}\right)$} & \multicolumn{2}{|c|}{ Soja $(2000 / 2001)$} & \multicolumn{2}{|c|}{ Milho (2001/2002) } & \multicolumn{2}{|c|}{ Soja $(2002 / 2003)$} & \multicolumn{2}{|c|}{ Milho (2003/2004) } \\
\hline & I (1999) & NI (2000) & Total & PC & PD & $\mathrm{PC}$ & PD & $\mathrm{PC}$ & PD & $\mathrm{PC}$ & PD \\
\hline & & $---\left(t^{h a-1}\right)--$ & - & & & & 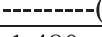 & $\left.\mathrm{ha}^{-1}\right)-\cdots$ & & & \\
\hline 1 & 0 & 0 & 0 & $1.235 \mathrm{f}$ & $1.281 \mathrm{f}$ & $2.644 d$ & $1.480 \mathrm{e}$ & $2.177 \mathrm{c}$ & $1.879 \mathrm{~d}$ & $7.363 \mathrm{~d}$ & $5.437 \mathrm{e}$ \\
\hline 2 & 2 & 0 & 2 & $1.585 \mathrm{~cd}$ & $1.595 \mathrm{~cd}$ & $6.769 \mathrm{~b}$ & $5.665 \mathrm{c}$ & $2.875 \mathrm{ab}$ & 2.934ab & $10.204 a b$ & $10.005 \mathrm{ab}$ \\
\hline 3 & 4 & 0 & 4 & $1.738 \mathrm{ab}$ & $1.684 \mathrm{abc}$ & $7.928 \mathrm{a}$ & $6.871 \mathrm{~b}$ & $2.934 \mathrm{ab}$ & $2.930 \mathrm{ab}$ & $10.544 \mathrm{a}$ & $10.419 a$ \\
\hline $4^{(2)}$ & 4 & 0 & 4 & $1.651 \mathrm{bcd}$ & $-(5)$ & $5.656 \mathrm{c}$ & - & $2.937 \mathrm{ab}$ & - & $9.286 \mathrm{c}$ & - \\
\hline $5^{(3)}$ & 0 & 2 & 2 & - & $1.416 \mathrm{e}$ & - & $2.909 \mathrm{~d}$ & - & $2.804 \mathrm{~b}$ & - & $8.977 \mathrm{c}$ \\
\hline $6^{(3)}$ & 0 & 4 & 4 & - & $1.571 \mathrm{~cd}$ & - & $3.229 \mathrm{~d}$ & - & $2.737 \mathrm{~b}$ & - & $9.000 \mathrm{c}$ \\
\hline $7^{(3)}$ & 2 & 2 & 4 & - & $1.566 \mathrm{~d}$ & - & $5.797 \mathrm{c}$ & - & $2.938 \mathrm{ab}$ & - & $9.811 b$ \\
\hline $8^{(3)}$ & 3 & 1 & 4 & - & $1.788 \mathrm{a}$ & - & $6.641 \mathrm{~b}$ & - & $3.133 \mathrm{a}$ & - & $10.386 a$ \\
\hline $9^{(4)}$ & 0 & 1 & 4 & - & $1.244 \mathrm{f}$ & - & $2.729 \mathrm{~d}$ & - & $2.790 \mathrm{~b}$ & - & $8.816 \mathrm{c}$ \\
\hline
\end{tabular}

(1)Médias seguidas da mesma letra, para cada cultura, não diferem entre si a 5\% de probabilidade pelo teste de Duncan. (2)Tratamento sem plantas de cobertura, somente com PC. (3)Tratamentos somente com PD. (4)Tratamento somente com PD, com aplicação anual de 1 t ha-1 de calcario. (5) Inexistente. 


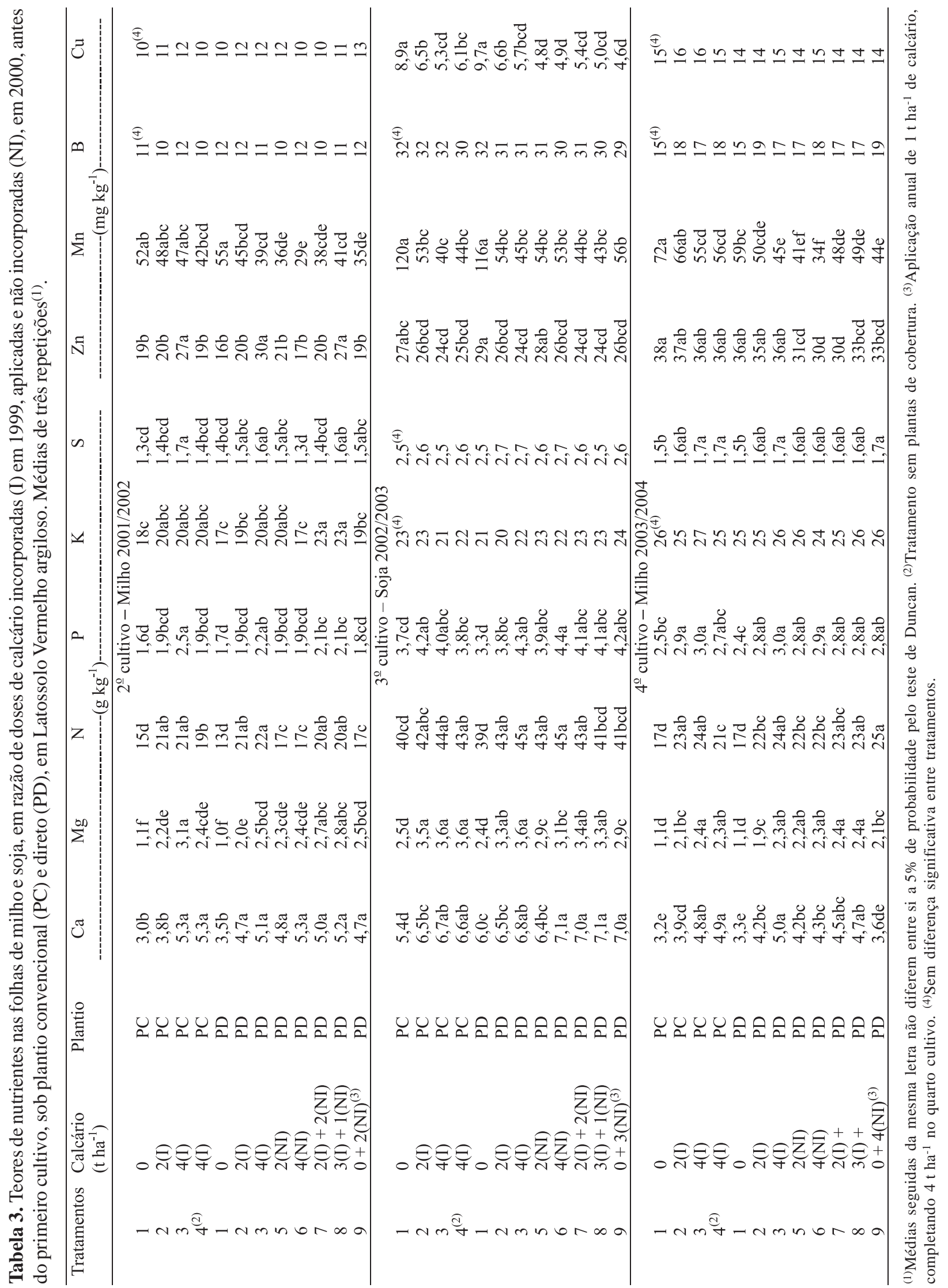


nibilidade de P no solo (Silva et al., 1997). Em 2001/2002, os menores teores de $\mathrm{Mg}, \mathrm{P}, \mathrm{S}$ e $\mathrm{Zn}$ nas folhas do milho ocorreram no tratamento 4 , sem plantas de cobertura, quando comparado com a mesma dose de calcário com plantas de cobertura (tratamento 3) (Tabela 3). No cultivo de 2003/2004, a diferença entre esses tratamentos só foi significativa para o nitrogênio. Nesse tratamento, foram produzidas e incorporadas ao solo $5.159 \mathrm{~kg} \mathrm{ha}^{-1}$ e $6.032 \mathrm{~kg} \mathrm{ha}^{-1}$ de matéria seca de mucuna, respectivamente, em 2001 e 2003 (Tabela 4). Entretanto, isso não se verifica na soja (2002/2003), cujos tratamentos 3-PC e 4 apresentaram produtividades semelhantes, apesar de terem sido incorporados $7.067 \mathrm{~kg} \mathrm{ha}^{-1}$ de matéria seca de milheto no tratamento 3. Deve-se considerar que existem diferenças entre resíduos de gramíneas (milheto) e de leguminosas (mucuna), principalmente na relação $\mathrm{C} / \mathrm{N}$, que resultam em diferentes taxas de decomposição e de aportes de nutrientes no solo (Carvalho et al., 1996; Amabile et al., 1999).

A produtividade do milho em resposta à aplicação de calcário sem incorporação no sistema plantio direto foi inferior em relação ao calcário incorporado. Nas doses 2 e $4 \mathrm{t} \mathrm{ha}^{-1}$ de calcário não incorporadas (tratamentos 5 e 6 ), a produtividade foi inferior, respectivamente, em 1,9 e 3,6 t ha ${ }^{-1}$ de grãos em 2001/2002 e inferior em 1,0 e 1,4 t ha ${ }^{-1}$ de grãos em 2003/2004, em relação às mesmas doses incorporadas (tratamentos 2 e 3). Esse comportamento pode ter sido decorrente da menor absorção de nutrientes, pois, no PD com calcário sem incorporação, principalmente na dose de $4 \mathrm{t} \mathrm{ha}^{-1}$, as plantas mostraram menores teores de $\mathrm{N}, \mathrm{S}, \mathrm{Zn}$ e Mn que as do tratamento 4 (Tabela 3). Em relação à soja em 2002/2003, essas diferenças não foram significativas.

Em PD com o calcário não incorporado, a resposta do milho, em 2001/2002, foi também proporcional à quantidade aplicada (Tabela 2), pois a produtividade de grãos na dose de $2 \mathrm{t} \mathrm{ha} \mathrm{a}^{-1}$ não incorporada (tratamento 5 ) foi semelhante à obtida quando se aplicou essa mesma dose em parcelas de $1 \mathrm{t} \mathrm{ha} \mathrm{a}^{-1}$ sem incorporação, antes de cada plantio (tratamento 9). No cultivo de 2003/2004, esse comportamento se repetiu, obtendo-se a mesma produtividade nos tratamentos 6 e 9 com o total de $4 \mathrm{t} \mathrm{ha}^{-1}$ de calcário aplicadas totalmente no início ou em quatro parcelas anuais de $1 \mathrm{t} \mathrm{ha}^{-1}$. Miranda (1993) constatou que soja e trigo em rotação apresentaram aumentos gradativos de produtividade em razão da utilização parcial do calcário no sulco de semeadura a cada cultivo, sendo semelhante ao total aplicado inicialmente, quando se completou a mesma quantidade de calcário.

Quanto ao parcelamento da dose de $4 \mathrm{t} \mathrm{ha}^{-1}$ de calcário em PD (tratamentos 7 e 8), a resposta do milho, em 2001/2002, foi proporcional à parte da dose que foi incorporada. Com a incorporação de $2 \mathrm{t} \mathrm{ha}^{-1}$, inicialmente, e aplicação de $2 \mathrm{t} \mathrm{ha}^{-1}$ na superfície antes do primeiro plantio, a produtividade foi semelhante à produzida com $2 \mathrm{t} \mathrm{ha}^{-1}$ incorporada inicialmente. Quando foram incorporadas $3 \mathrm{t} \mathrm{ha}^{-1}$ inicialmente e aplicada $1 \mathrm{t} \mathrm{ha}^{-1}$ na superfície antes do primeiro plantio, a produtividade foi semelhante à obtida com $4 \mathrm{t} \mathrm{ha}^{-1}$ incorporadas inicialmente. A produtividade da soja em 2002/2003 foi semelhante para todas as doses de calcário a partir de $2 \mathrm{t} \mathrm{ha}^{-1}$, não mostrando claramente o efeito do parcelamento do calcário em plantio direto. Entretanto, a produtividade no tratamento 8 , em que três quartos da dose foram incorporados inicialmente, foi superior à do tratamento 9, com aplicação anual de um quarto da dose na superfície. Em 2003/2004, as produtividades do milho foram semelhantes nos tratamentos com $4 \mathrm{t} \mathrm{ha}^{-1}$ de calcário incorporadas inicialmente (tratamento 3) ou aplicadas de forma parcelada (tratamento 8) com $3 \mathrm{t} \mathrm{ha}^{-1}$ incorporadas e $1 \mathrm{t} \mathrm{ha}^{-1}$ superficial. Contudo, quando o calcário foi aplicado na superfície com a dose total (tratamento 6) ou parcelada anualmente (tratamento 9) em

Tabela 4. Produtividade de matéria seca $\left(\mathrm{kg} \mathrm{ha}^{-1}\right)$ de mucuna e milheto no período seco, respectivamente, após os cultivos de soja e milho, em razão de doses de calcário incorporadas (I) em 1999, aplicadas e não incorporadas (NI) em 2000, antes do primeiro cultivo, sob plantio convencional (PC) e direto (PD), em Latossolo Vermelho argiloso. Médias de três repetições ${ }^{(1)}$.

\begin{tabular}{|c|c|c|c|c|c|c|c|c|}
\hline \multirow[t]{2}{*}{ Tratamentos } & \multicolumn{2}{|c|}{ Calcário $\left(\mathrm{t} \mathrm{ha}^{-1}\right)$} & \multicolumn{2}{|c|}{ Mucuna - 2001} & \multicolumn{2}{|c|}{ Milheto - 2002} & \multicolumn{2}{|c|}{ Mucuna - 2003} \\
\hline & I (1999) & NI (2000) & $\mathrm{PC}$ & PD & $\mathrm{PC}$ & PD & $\mathrm{PC}$ & PD \\
\hline 1 & 0 & 0 & $2.943 d$ & $2.958 \mathrm{~d}$ & $4.333 d$ & $3.600 d$ & $3.750 \mathrm{~d}$ & $3.282 \mathrm{~d}$ \\
\hline 2 & 2 & 0 & $4.037 \mathrm{bc}$ & $4.401 \mathrm{abc}$ & $5.267 \mathrm{bc}$ & $4.933 \mathrm{~cd}$ & $5.102 b c$ & $4.899 c$ \\
\hline 3 & 4 & 0 & $5.159 \mathrm{a}$ & $4.886 \mathrm{abc}$ & $7.067 \mathrm{a}$ & $6.400 \mathrm{ab}$ & $6.032 \mathrm{a}$ & $5.566 \mathrm{ab}$ \\
\hline 5 & 0 & 2 & $-(2)$ & $4.095 \mathrm{bc}$ & - & $4.867 \mathrm{~cd}$ & - & $4.884 c$ \\
\hline 6 & 0 & 4 & - & $3.764 \mathrm{~cd}$ & - & $5.133 b c$ & - & $4.726 c$ \\
\hline
\end{tabular}

${ }^{(1)}$ Médias seguidas da mesma letra, para cada cultura, não diferem entre si a 5\% de probabilidade pelo teste de Duncan. (2)Inexistente. 
$\mathrm{PD}$, as produtividades foram inferiores em relação a mesma dose incorporada (tratamento 3).

A não incorporação do calcário se mostrou relativamente ineficiente, particularmente em relação ao milho, quer tenha sido ele aplicado totalmente antes do primeiro plantio quer parceladamente a cada plantio. Dados de Pöttker \& Ben (1998) e Caires et al. (2002) mostram que essa técnica pode ser utilizada eficientemente na reaplicação de calcário em solos já corrigidos e cultivados. Esse seria o caso do tratamento 8, em que se faria uma complementação da calagem, pela adição de pequenas doses de calcário na superfície no sistema plantio direto.

Alguns autores têm pesquisado a eficiência da aplicação superficial de calcário sem incorporação, no sistema plantio direto, na Região Sul do Brasil. Embora se tenha observado a ocorrência de alterações químicas no solo, não têm sido observados efeitos sobre a produtividade das culturas (Caires et al., 2002; Pires et al., 2003), provavelmente em função das condições adequadas de fertilidade do solo. Segundo esses autores, a produtividade de milho variou entre 8 e $10 \mathrm{t} \mathrm{ha}^{-1}$, quando não se aplicou calcário. É muito importante considerar este aspecto quando se extrapola dados de uma região para outra, pois essas produtividades estão entre as máximas obtidas quando se utiliza calcário na Região do Cerrado. Nessa região, pode não ocorrer nenhuma produtividade do milho na ausência da calagem, mesmo com a fertilidade do solo corrigida (Gonzalez-Erico et al., 1979; Miranda \& Miranda, 2000). No presente trabalho, constatou-se que o cultivo de plantas na entressafra, incorporando a palhada em plantio convencional ou mantendo-a na superfície em plantio direto pode, com o tempo de cultivo, promover acréscimos de produtividade do milho em solos ácidos, mesmo sem a utilização de calcário. Adicionalmente, a utilização anual de adubação de manutenção, com fornecimento de Ca e P presentes no adubo, pode ter atenuado os efeitos da acidez no tratamento sem calcário.

Houve pouca efetividade do calcário aplicado na superfície sem incorporação quando se começou o cultivo do solo muito ácido. Quando o calcário foi incorporado com PC e PD, a resposta inicial foi maior no plantio convencional. Na comparação da produtividade de diversas culturas nos dois sistemas de cultivo, constatase variação nos dados, podendo ocorrer produtividades semelhantes em ambos, superiores em plantio direto ou superiores em plantio convencional (Muzzili, 1983;
Santos et al., 1995). No decorrer do cultivo, ocorre aumento de $\mathrm{pH}$ e de disponibilidade de nutrientes no sistema de plantio direto (Sidiras \& Pavan, 1985), que pode refletir-se na maior produtividade das culturas nesse sistema.

Houve incremento nos teores foliares de Ca e Mg do milho com as doses de calcário e de outros nutrientes que, na dose recomendada de $4 \mathrm{t} \mathrm{ha} \mathrm{a}^{-1}$ de calcário incorporada (Tabela 3), estão dentro da faixa considerada adequada (Cantarella et al., 1996). Teores semelhantes foram, também, obtidos com essa cultura em solo de cerrado (Miranda \& Miranda, 2000). Oliveira et al. (1997) também observaram redução significativa de absorção de Mn pela cultura do milho quando se aplicou calcário, porém, neste trabalho, essas diferenças foram maiores para a soja cultivada em 2002/2003.

Em relação às plantas de cobertura, mucuna e milheto, cultivadas no período seco, houve aumento significativo de produtividade de matéria seca em função das doses de calcário (Tabela 4). A produtividade máxima foi obtida nas parcelas que receberam $4 \mathrm{t} \mathrm{ha}^{-1}$ de calcário incorporadas inicialmente. A mucuna e o milheto foram cultivados com plantio direto, e a produtividade de matéria seca foi semelhante nas áreas cultivadas anteriormente em plantio convencional ou direto.

Os resultados da análise do solo, antes do segundo cultivo com milho, mostraram a reação do calcário no solo depois do cultivo da soja e da mucuna, após dois anos da aplicação para as doses incorporadas e, após um ano da aplicação, para as não incorporadas (Tabela 5). Houve, em geral, uma variabilidade nos atributos químicos do solo a partir da camada de $0-5 \mathrm{~cm}$ em que, mesmo para o calcário incorporado, os teores de Ca e Mg trocáveis e a saturação por bases tendem a decrescer e o teor de Al trocável tende a aumentar com a profundidade. Nas parcelas nas quais o calcário não foi incorporado (NI-PD), os maiores valores de $\mathrm{pH}, \mathrm{Ca}+\mathrm{Mg}$ e de saturação por bases $(\mathrm{V})$ ocorreram na camada de 0-5 cm. Na camada de 5-10 cm, a condição química é semelhante à das mesmas doses incorporadas, mas na camada de 10-20 cm não ocorreu efeito da calagem, e os dados da análise são semelhantes aos do solo natural sem calcário. Essa camada, após quatro anos de aplicação superficial de $4 \mathrm{t} \mathrm{ha}^{-1}$ de calcário, apresentava 46\% de saturação por alumínio.

Antes do terceiro cultivo com soja (2002/2003) e do quarto cultivo com milho (2003/2004), a tendência foi a mesma observada antes do plantio do milho em 2000/2001, e no tratamento que recebeu $4 \mathrm{t} \mathrm{ha}^{-1}$ de calcário incorpo- 
radas, os atributos químicos foram semelhantes em todas as camadas amostradas para o PC. Nas parcelas nas quais o calcário foi aplicado na superfície sem incorporação em plantio direto, os atributos químicos se mantiveram praticamente inalterados mediante cultivos sucessivos, com maiores valores de $\mathrm{pH}, \mathrm{Ca}+\mathrm{Mg}$ e de saturação por bases (V) na camada de $0-5 \mathrm{~cm}$. Na camada de 5-10 cm, essas variáveis são semelhantes às das mesmas doses incorporadas e, na camada de 10$20 \mathrm{~cm}$, são iguais às do solo natural, mesmo após três anos de aplicação do calcário e após dois cultivos de mucuna e um cultivo de milho, soja e milheto. Conse- qüentemente, as condições de acidez nessa camada podem ter sido limitantes ao crescimento das raízes do milho, resultando na redução de produtividade, embora não se tenha avaliado o crescimento de raízes no solo. Pöttker \& Ben (1998) também observaram maior efeito do calcário não incorporado nos atributos químicos da camada de $0-5 \mathrm{~cm}$ e, em menor grau, na camada de 5-10 cm. Pires et al. (2003) observaram efeito positivo da aplicação do calcário na superfície em solo argiloso até a profundidade de $0-5 \mathrm{~cm}$. Em áreas já cultivadas, o calcário de manutenção aplicado na superficie promoveu aumento do $\mathrm{pH}$ e redução do alumínio trocável

Tabela 5. Valores de pH em água (1:2,5), alumínio e cálcio+magnésio trocáveis e saturação por bases nas camadas de 0-5, 5-10 e 10-20 cm do solo antes do plantio, em razão de doses de calcário incorporadas (I) em 1999, aplicadas e não incorporadas (NI) em 2000, antes do primeiro cultivo, sob plantio convencional (PC) e direto (PD), em Latossolo Vermelho argiloso. Médias de três repetições.

\begin{tabular}{|c|c|c|c|c|c|c|c|c|c|c|c|c|c|}
\hline \multirow{3}{*}{$\begin{array}{l}\text { Calcário } \\
\left(\mathrm{t} \mathrm{ha}^{-1}\right)\end{array}$} & \multirow{3}{*}{$\begin{array}{l}\text { Profundidade } \\
\text { (cm) }\end{array}$} & \multicolumn{3}{|c|}{$\mathrm{pH} \mathrm{H} \mathrm{H}_{2} \mathrm{O}$} & \multicolumn{3}{|c|}{$\mathrm{Al}^{3+}$} & \multicolumn{3}{|c|}{$\mathrm{Ca}^{2+}+\mathrm{Mg}^{2+}$} & \multicolumn{3}{|c|}{ Sat. por bases $(\mathrm{V})$} \\
\hline & & $\mathrm{I}-\mathrm{PC}$ & I-PD & NI-PD & $\mathrm{I}$ I-PC & I-PD & NI-PD & $\mathrm{I}-\mathrm{PC}$ & I-PD & $\overline{\text { NI-PD }}$ & I-PC & I-PD & NI-PD \\
\hline & & & & & -------- & - & $---(\mathrm{cmol}$ & $\left.\mathrm{dm}^{-3}\right)$ & ------ & ---------- & & $----(\%$ & \\
\hline \multirow{4}{*}{0} & & \multicolumn{12}{|c|}{ Antes do $2^{\mathrm{o}}$ cultivo - Milho 2001/2002 } \\
\hline & $0-5$ & 4,7 & 4,7 & $-(1)$ & 0,7 & 0,6 & - & 0,6 & 0,6 & - & 10 & 9 & - \\
\hline & $5-10$ & 4,7 & 4,7 & - & 0,8 & 0,7 & - & 0,3 & 0,4 & - & 5 & 7 & - \\
\hline & $10-20$ & 4,7 & 4,6 & - & 0,8 & 0,7 & - & 0,3 & 0,3 & - & 4 & 4 & - \\
\hline \multirow[t]{3}{*}{2} & $0-5$ & 5,3 & 5,3 & 5,9 & 0,2 & 0,2 & 0,0 & 1,7 & 1,7 & 3,4 & 25 & 24 & 47 \\
\hline & $5-10$ & 5,2 & 5,2 & 5,1 & 0,2 & 0,3 & 0,3 & 1,4 & 1,4 & 1,3 & 20 & 21 & 17 \\
\hline & $10-20$ & 5,1 & 5,2 & 4,6 & 0,3 & 0,4 & 0,9 & 1,0 & 0,7 & 0,2 & 15 & 11 & 4 \\
\hline \multirow[t]{3}{*}{4} & $0-5$ & 5,5 & 5,4 & 6,3 & 0,1 & 0,1 & 0,0 & 2,7 & 2,4 & 5,1 & 40 & 34 & 76 \\
\hline & $5-10$ & 5,5 & 5,5 & 5,7 & 0,1 & 0,1 & 0,1 & 2,4 & 2,2 & 2,4 & 35 & 32 & 35 \\
\hline & $10-20$ & 5,5 & 5,4 & 4,6 & 0,1 & 0,1 & 1,0 & 1,9 & 1,7 & 0,2 & 27 & 25 & 4 \\
\hline \multicolumn{14}{|c|}{ Antes do $3^{0}$ cultivo - Soja $2002 / 2003$} \\
\hline \multirow[t]{3}{*}{0} & $0-5$ & 5,1 & 5,1 & - & 0,5 & 0,6 & - & 0,6 & 0,7 & - & 10 & 11 & - \\
\hline & $5-10$ & 4,8 & 4,9 & - & 0,6 & 0,7 & - & 0,5 & 0,4 & - & 7 & 7 & - \\
\hline & $10-20$ & 4,7 & 4,8 & - & 0,7 & 0,7 & - & 0,4 & 0,3 & - & 5 & 5 & - \\
\hline \multirow[t]{3}{*}{2} & $0-5$ & 5,4 & 5,4 & 6,0 & 0,2 & 0,1 & 0,0 & 1,7 & 2,0 & 3,9 & 25 & 27 & 51 \\
\hline & $5-10$ & 5,3 & 5,2 & 5,6 & 0,3 & 0,3 & 0,2 & 1,4 & 1,3 & 1,5 & 20 & 20 & 19 \\
\hline & $10-20$ & 5,2 & 5,1 & 4,8 & 0,3 & 0,5 & 0,6 & 1,2 & 0,9 & 0,4 & 18 & 13 & 6 \\
\hline \multirow[t]{3}{*}{4} & $0-5$ & 5,4 & 5,5 & 6,3 & 0,1 & 0,0 & 0,0 & 2,6 & 2,9 & 5,6 & 35 & 38 & 79 \\
\hline & $5-10$ & 5,5 & 5,5 & 5,6 & 0,1 & 0,1 & 0,1 & 2,5 & 2,4 & 2,7 & 34 & 32 & 37 \\
\hline & $10-20$ & 5,6 & 5,6 & 5,2 & 0,0 & 0,1 & 0,6 & 2,7 & 2,5 & 0,7 & 35 & 35 & 9 \\
\hline \multirow{4}{*}{0} & & \multicolumn{12}{|c|}{ Antes do $4^{\circ}$ cultivo - Milho 2003/2004 } \\
\hline & $0-5$ & 4,9 & 4,8 & - & 0,5 & 0,5 & - & 0,7 & 0,8 & - & 11 & 11 & - \\
\hline & $5-10$ & 4,8 & 4,8 & - & 0,5 & 0,6 & - & 0,4 & 0,5 & - & 6 & 7 & - \\
\hline & $10-20$ & 4,8 & 4,6 & - & 0,6 & 0,6 & - & 0,5 & 0,5 & - & 7 & 7 & - \\
\hline \multirow[t]{3}{*}{2} & $0-5$ & 5,2 & 5,1 & 5,5 & 0,2 & 0,1 & 0,1 & 1,8 & 2,3 & 4,1 & 26 & 30 & 50 \\
\hline & $5-10$ & 5,0 & 4,9 & 5,0 & 0,3 & 0,3 & 0,3 & 1,3 & 1,3 & 1,9 & 19 & 18 & 17 \\
\hline & $10-20$ & 5,1 & 5,0 & 4,8 & 0,3 & 0,5 & 0,6 & 1,2 & 1,2 & 0,5 & 18 & 16 & 7 \\
\hline \multirow[t]{3}{*}{4} & $0-5$ & 5,3 & 5,5 & 6,4 & 0,0 & 0,1 & 0,0 & 2,6 & 3,1 & 5,3 & 37 & 42 & 74 \\
\hline & $5-10$ & 5,2 & 5,4 & 5,4 & 0,1 & 0,1 & 0,2 & 2,6 & 2,3 & 2,5 & 34 & 34 & 35 \\
\hline & $10-20$ & 5,4 & 5,4 & 4,9 & 0,1 & 0,1 & 0,6 & 2,6 & 2,3 & 0,7 & 35 & 33 & 9 \\
\hline
\end{tabular}

(1)Inexistente. 
principalmente até $10 \mathrm{~cm}$ de profundidade (Caires et al., 1998). Segundo Moreira et al. (2001), essas alterações nas camadas subsuperficiais podem atingir profundidades maiores, até $30 \mathrm{~cm}$, e são proporcionais às doses de calcário aplicadas e ao tempo de aplicação na superfície do solo.

\section{Conclusões}

1. Doses adequadas de calcário promovem aumentos de produtividade da soja e do milho cultivados em sistemas de plantio direto e convencional.

2. No solo com acidez elevada, o calcário incorporado ao solo promove maior produtividade de milho que $o$ não incorporado, em plantio direto.

3. A aplicação superficial do calcário sem incorporação é eficiente na correção da acidez do solo na camada de $0-5 \mathrm{~cm}$.

4. O efeito do calcário depende do tempo decorrido da aplicação e do volume de solo corrigido.

\section{Referências}

AMABILE, R.F.; FANCELLI, A.L.; CARVALHO, A.M. Absorção de N, P e K por espécies de adubos verdes cultivadas em diferentes épocas e densidades num Latossolo Vermelho-Escuro argiloso sob Cerrados. Revista Brasileira de Ciência do Solo, v.23, p.837845, 1999.

ARSHAD, M.A.; GILL, K.S. Field pea response to liming of an acid soil under two tillage systems. Canadian Journal of Soil Science, v.76, p.549-555, 1996.

BAYER, C.; MIELNICZUK, J. Características químicas do solo afetadas por métodos de preparo e sistemas de cultura. Revista Brasileira de Ciência do Solo, v.21, p.105-112, 1997.

CAIRES, E.F.; BARTH, G.; GARBUIO, F.J.; KUSMAN, M.T. Correção da acidez do solo, crescimento radicular e nutrição do milho de acordo com a calagem na superfície em sistema plantio direto. Revista Brasileira de Ciência do Solo, v.26, p.1011-1022, 2002.

CAIRES, E.F.; CHUEIRI, W.A.; MADRUGA, E.F.; FIGUEIREDO, A. Alterações de características químicas do solo e resposta da soja ao calcário e gesso aplicados na superfície em sistema de cultivo sem preparo do solo. Revista Brasileira de Ciência do Solo, v.22, p.27-34, 1998.

CANTARELLA, H.; RAIJ, B. van; CAMARGO, C.E.O. Cereais. In: RAIJ, B. van; CANTARELLA, H.; QUAGGIO, J.A.; FURLANI, A.M.C. (Ed.). Recomendações de adubação e calagem para o Estado de São Paulo. 2.ed. Campinas: Instituto Agronômico, 1996. 285p. (Boletim Técnico, 100).

CARVALHO, A.M. de; CORREIA, J.R.; BLANCANEAUX, P.; FREITAS, L.R.S.; MENEZES, H.A.; PEREIRA, J.; AMABILE, R.F. Caracterização de espécies de adubos verdes para milho em Latossolo Vermelho-Escuro originalmente sob cerrado. In:
SIMPÓSIO SOBRE O CERRADO, 8.; INTERNATIONAL SYMPOSIUM ON TROPICAL SAVANNAS, 1., 1996, Brasília. Biodiversidade e produção sustentável de alimentos e fibras nos cerrados. Anais. Planaltina: Embrapa-CPAC, 1996. p.384-388.

COSTA, F.J.S.A.; BOULDIN, D.R.; SUHET, A.R. Evaluation of N recovery from mucuna placed on the surface or incorporated in a Brazilan oxisol. Plant and Soil, v.124, p.91-96, 1990.

EMBRAPA. Serviço Nacional de Levantamento de Solos (Rio de Janeiro, RJ). Manual de métodos de análises de solo. Rio de Janeiro, 1979. Não paginado.

GOEDERT, W.J. Management of the Cerrado soils of Brazil: a review. Journal of Soil Science, v.34, p.405-428, 1983.

GONZALEZ-ERICO, E.; KAMPRATH, E.J.; NADERMAN, G.C.; SOARES, W.V. Effect of depth of lime incorporation on the growth of corn on an Oxisol of Central Brasil. Soil Science Society of America Journal, v.46, p.1155-1158, 1979.

KLEPKER, D.; ANGHINONI, I. Características químicas e físicas do solo afetadas por métodos de preparo e modos de adubação. Revista Brasileira de Ciência do Solo, v.19, p.395-401, 1995.

MALAVOLTA, E.; VITTI, G.C.; OLIVEIRA, S.A. de. Avaliação do estado nutricional das plantas: princípios e aplicações. Piracicaba, Potafos, 1997. 319p.

MIRANDA, L.N. de. Resposta da sucessão soja-trigo a doses e modos de aplicação de calcário em solo glei pouco húmico. Revista Brasileira de Ciência do Solo, v.17, p.75-82, 1993.

MIRANDA, L.N. de; MIRANDA, J.C.C. de. Efeito residual do calcário na produção de milho e soja em solo glei pouco húmico. Revista Brasileira de Ciência do Solo, v.24, p.209-215, 2000.

MOREIRA, S.G.; KIEHL, J.C.; PROCHNOW, L.I.; PAULETTI, V. Calagem em sistema de semeadura direta e efeitos sobre a acidez do solo, disponibilidade de nutrientes e produtividade de milho e soja. Revista Brasileira de Ciência do Solo, v.25, p.71-81, 2001.

MUZILLI, O. de. Influência do sistema de plantio direto, comparado ao convencional, sobre a fertilidade da camada arável do solo. Revista Brasileira de Ciência do Solo, v.7, p.95-102, 1983.

NOVAIS, R.F.; NEVES, J.C.L.; BARROS, N.F.; SEDIYAMA, T. Deficiência de manganês em plantas de soja cultivadas em solos de cerrado. Revista Brasileira de Ciência do Solo, v.13, p.199-204, 1989.

OLIVEIRA, E.L. de; PARRA, M.S.; COSTA, A. Resposta da cultura do milho em um latossolo vermelho-escuro álico à calagem. Revista Brasileira de Ciência do Solo, v.21, p.65-70, 1997.

OLIVEIRA, E.L. de; PAVAN, M.A. Control of soil acidity in notillage system for soybean production. Soil and Tillage Research, v.38, p.47-57, 1996.

PIRES, F.R.; SOUZA, C.M.; QUEIROZ, D.M.; MIRANDA, G.V.; GALVÃO, J.C.C. Alteração de atributos químicos do solo e estado nutricional e características agronômicas de plantas de milho, considerando as modalidades da calagem em plantio direto. Revista Brasileira de Ciência do Solo, v.27, p.121-131, 2003.

PÖTTKER, D.; BEN, J.R. Calagem para uma rotação de culturas no sistema de plantio direto. Revista Brasileira de Ciência do Solo, v.22, p.675-684, 1998. 
RECHCIGL, J.E.; WOLF, D.D.; RENEAU, R.B.; KROONTJE, W. Influence of surface liming on the yield and nutrient concentration of alfafa established using no-tillage techniques. Agronomy Journal, v.77, p.956-959, 1985.

SANTOS, H.P. dos; TOMM, G.O.; LHAMBY, J.C.B. Plantio direto versus convencional: efeito na fertilidade do solo e no rendimento de grãos de culturas em rotação com cevada. Revista Brasileira de Ciência do Solo, v.19, p.449-454, 1995.

SAS INSTITUTE (Cary, Estados Unidos). Statistical analysis systems user's guide: version 6. $4^{\text {th }}$ ed. Cary, 1989. v.1.
SIDIRAS, N.; PAVAN, M.A. Influência do sistema de manejo do solo no seu nível de fertilidade. Revista Brasileira de Ciência do Solo, v.9, p.249-254, 1985.

SILVA, M.L.N.; CURI, N.; BLANCANEAUX, P.; LIMA, J.M. de; CARVALHO, A.M. de. Rotação adubo verde-milho e adsorção de fósforo em Latossolo Vermelho-Escuro. Pesquisa Agropecuária Brasileira, v.32, p.649-654, 1997.

WILSON, D.O.; HARGROVE, W.L. Release of nitrogen from crimson clover residue under two tillage systems. Soil Science Society of America Journal, v.50, p.1251-1254, 1986.

Recebido em 3 de setembro de 2004 e aprovado em 11 de janeiro de 2005 